BULLETIN Bulletin hispanique

HispaniquE Université Michel de Montaigne Bordeaux

113-1 | 2011

Actes de 2 colloques

\title{
Construir un mercado, renovar las lecturas y hacer nuevos lectores
}

La Librería de Frédéric Rosa (1824-1850)

Laura Suárez de la Torre

\section{(2) OpenEdition}

\section{Journals}

Edición electrónica

URL: http://journals.openedition.org/bulletinhispanique/1551

DOI: 10.4000/bulletinhispanique.1551

ISSN: 1775-3821

\section{Editor}

Presses universitaires de Bordeaux

\section{Edición impresa}

Fecha de publicación: 1 junio 2011

Paginación: 469-483

ISBN: 978-2-86781-740-3

ISSN: 0007-4640

Referencia electrónica

Laura Suárez de la Torre, «Construir un mercado, renovar las lecturas y hacer nuevos lectores »,

Bulletin hispanique [En línea], 113-1 | 2011, Publicado el 01 junio 2014, consultado el 01 mayo 2019.

URL : http://journals.openedition.org/bulletinhispanique/1551 ; DOI : 10.4000/bulletinhispanique.1551 


\title{
Construir un mercado, renovar las lecturas y hacer nuevos lectores. La Librería de Frédéric Rosa (1824-1850)
}

\author{
Laura SuÁrez de la Torre \\ Instituto Mora México
}

L'article porte sur les relations commerciales entre la France et le Mexique dans la première moitié du XIX siècle à travers le commerce des livres et il cherche à démontrer comment les lecteurs ont été décisifs pour définir le marché. Le Catalogue de la Librairie de Frédéric Rosa permet de percevoir les goûts des lecteurs et d'offrir quelques exemples.

El artículo trata de la relación comercial entre Francia y México en la primera mitad del siglo XIX a través del comercio de libros y busca demostrar cómo los lectores fueron definiendo el mercado. A partir del Catálogo de la Librería de Frédéric Rosa se perciben los gustos de los lectores y se plantean algunos ejemplos.

This article tackles with the commercial relation between France and Mexico during the first half of the nineteenth century, through books trading, seeking to demonstrate how readers had a decisive importance in the definition of the market. The Catalog of Frederic Rosa's Bookshop allows us to perceive the readers' tastes as well as offering us a few examples of them.

Mots-clés : Commerce - France-Mexique - Commerce du livre - Lecteurs.

Bulletin Hispanique, Tome 113, n 1 - juin 2011 - p. 469 à 483. 
T a ciudad de México desde la época colonial, siglo XVI, se había Lonstituido en el centro político, religioso y cultural de la Nueva España. En ese siglo se estableció la imprenta y la Universidad y también diversos colegios y seminarios. Con el tiempo devino en la ciudad con mayor número de habitantes, calculándose, en los albores del siglo XIX una población entre 100000 y 130 000. Cuando en 1821 México logró su independencia, la capital continuó siendo el eje político, económico y cultural por excelencia. Como centro político, abrigó los poderes nacionales y congregó a los hombres más destacados de las distintas regiones del país, en tanto representantes o en cuanto funcionarios públicos constituyendo, una elite cultural desde la ciudad de México. Como centro cultural poseía, como ya señalé, la Universidad, que fue suprimida en 1833, los colegios, los seminarios, las bibliotecas religiosas, los teatros, y fue abrigando a las asociaciones literarias y a los gabinetes de lectura, más importantes que se crearon a lo largo del XIX. Allí se encontraban las principales imprentas, las librerías ancestrales que comerciaron los impresos tradicionales -de carácter religioso, científico o los autores de la cultura clásica-, y, después de la Independencia, con una legislación más propicia ${ }^{1}$, se fueron estableciendo lógicamente nuevos negocios urbanos como talleres de imprenta, librerías, así como cafés, negocios, impulsados por una nueva generación nacida al final del siglo XVIII y principios del XIX, negocios que estarían en clara relación con la letra impresa y en los que mexicanos y extranjeros se interesarían.

Para entender el cambio que se gestó a nivel comercial entre Europa y México y el interés que despertó entre los extranjeros, tenemos que señalar que gracias a la obra de Alexander von Humboldt, la imagen de México comenzó a mirarse como el cuerno de la abundancia ${ }^{2}$ y los extranjeros visualizaron al país como polo atractivo para emprender grandes y pequeñas empresas. La ciudad de México, abrió sus puertas a propios y a extraños, ampliando las expectativas económicas urbanas. Entre ellas, las imprentas y

1. Es pertinente señalar que desde 1810 se decretó la libertad de imprenta en España y sus colonias y que al independizarse México mantuvo esta política con algunas restricciones en relación con la religión y la autoridad.

2. Ver : Alexander von Humboldt, Essai politique sur le royaume de la Nouvelle Espagne, Paris, F. Schoell, 1811. También es necesario señalar que para quienes comenzaron a ofrecer libros en español, el mercado en España después del trienio liberal, se convirtió en una plaza complicada por la desaparición de la libertad de imprenta, mientras que en México la política tendiente a promover el intercambio comercial con las naciones europeas favoreció el interés de los extranjeros por comerciar con el nuevo país. 
las librerías tuvieron un sitio especial y a lo largo del siglo XIX el crecimiento de estos negocios, pudiéramos decir fue exponencial, proliferando en la ciudad de México como también en las distintas plazas, pues los privilegios reales y la censura habían desaparecido ${ }^{3}$. En este escenario de apertura y con necesidades que cubrir - políticas, educativas, culturales, tecnológicas ${ }^{4}$ la producción impresa nacional y extranjera adquirió gran importancia y los extranjeros incursionaron en el mercado mexicano, dadas las condiciones favorables que se presentaban, lo que ayudó a ampliar el comercio del libro en México y de los impresos, en general.

Con este trabajo quiero mostrar cómo el momento político-económico en México y en Francia favoreció una relación comercial que llevó a construcción de un nuevo mercado franco-mexicano. Asimismo me interesa presentar cómo los lectores fueron definiendo el mercado y cómo ello se puede visualizar a través de la librería francesa de Frédéric Rosa, en tanto eslabón importante para el comercio de libros entre Europa y América.

Para emprender este trabajo recurrí esencialmente a la Bibliographie de la France, al Feuilleton de la Librairie en France y al Catálogo de la Librería de Rosa como fuentes para lograr un acercamiento a la oferta editorial francesa orientada al mercado mexicano en la primera mitad del siglo XIX. Es pertinente señalar que en México no existen archivos específicos dedicados a preservar la memoria de las imprentas y librerías. La reconstrucción, por ende, la realicé a través de las fuentes arribas citadas y con ayuda de algunos materiales que localicé en México y en Francia que me sirvieron para dar seguimiento a la Librería de Rosa.

3. Con la restitución de la Constitución liberal de Cádiz en 1820, se proclamaron las libertades de pensamiento e imprenta, así como de trabajo. Ver Laura Suárez de la Torre, «Monumentos en tinta y papel...» en Erika Pani y Alicia Samerón (Coords.), Conceptualizar lo que se ve. Francois-Xavier Guerra, Historiador. Homenaje, México, Instituto Mora, 2004. Vale la pena mencionar que en el siglo XVIII y en los albores del XIX existían alrededor de una quincena de librerías y otros puntos de venta como lo fueron los conventos y los colegios que poseían sus propias imprentas. Ver Juana Zahar Vergara, Historia de las librerías de la ciudad de México. Evocación y presencia, México, UNAM, 2006.

4. Políticas porque el país iniciaba su construcción como nación independiente y requería de referentes para organizarse y gobernar; educativas porque los nuevos gobiernos estarían pugnando por mejorar la enseñanza; culturales, dado el interés que existió por instaurar asociaciones literarias y musicales; tecnológicas ya que se buscaba el progreso de la nueva nación. 


\section{Construir Un MERCADo}

Con la independencia de México el país pasó de ser una colonia controlada desde España a una nación que buscaba establecer libremente relaciones comerciales con las distintas potencias tanto de Europa como de América. México, como señalé, devino en un espacio importante para comerciar pues ofreció amplias ventajas a los intereses mercantiles de los países de Europa y a los Estados Unidos. Por eso las naciones europeas y Estados Unidos buscaron otorgar el reconocimiento al nuevo país y entablar primero relaciones de comercio y navegación y después establecer los convenios diplomáticos específicos. Estados Unidos ${ }^{5}$, Francia ${ }^{6}$, Gran Bretaña o Alemania muy pronto se interesaron en México como mercado potencial, como un sitio donde colocar sus mercancías excedentes. Los libros, los folletos, las estampas, los grabados y las litografías, impresos generalmente provenientes de Europa, encontrarían una salida pues los europeos interesados podrían comerciar directamente con México y ya no a través de España.

La nueva república, desde la perspectiva de los impresos, resultaba una opción importante por el número de habitantes, por los compradores viables habituales -políticos, religiosos, estudiantes, comerciantes, etc. ${ }^{7}$, por los proyectos educativos que surgirían de los intereses de las nuevas autoridades, por las necesidades de piedad cotidiana, por las aspiraciones de la elite dirigente, por las demandas propias de una nación en construcción, como mencioné. Por ello, diversos libreros extranjeros pusieron su mirada en México y se relacionaron muy tempranamente con el mercado mexicano. En

5. Estados Unidos otorgó el reconocimiento el 6 de abril de 1822 siendo el primer país, adelantándose a Gran Bretańa. La Doctrina Monroe fue proclamada el 2 de diciembre de 1823.

6. Sin haber otorgado el reconocimiento oficial, Francia se mostraba ampliamente interesada en comerciar con México. «En el Havre, en Burdeos y en Marsella, navieros y comerciantes anhelaban exportar directamente a las antiguas colonias españolas de América, evitando tener como intermediario a los Estados Unidos.» Jacques Penot, Primeros contactos diplomáticos entre México y Francia 1808-1838, México, Secretaría de Relaciones Exteriores, 1975, p. 42 (Colección del Archivo Histórico Mexicano. Obras Monográficas / 6). En el informe que envió el conde Louis Foucault al Ministro francés de Asuntos Extranjeros el enero de 1822, Francia podría comerciar con México: seda, quincallería, artículos de moda, armas y vinos. Podemos decir que, aunque los impresos no estaban contemplados, se abría para ellos un posible mercado. Ibid., p. 42.

7. Cristina Gómez, «Comercio y comerciantes del libro en la carrera de Indias: Cádiz y Veracruz, 1750-1778» en Historia Mexicana, El Colegio de México, enero-marzo, 2008, número 227, p. 621. 
la década de 1820 los libreros Seguin, Bouchon, Bossange, Masson, Rosa, Ackermann ya tenían intereses comerciales en la ciudad de México. Debo subrayar aquí que pese al analfabetismo reinante - del que no tenemos cifras precisas, pero que podemos inferir era muy elevado, alrededor del 90\%México se presentó como una buena opción para el comercio del impreso, con un futuro promisorio: una nación que se proyectaba y redefinía día a día, unos lectores atentos a las publicaciones y una elite interesada en las lecturas como alimento necesario para sus proyectos político-culturales.

La legislación que puso en marcha el país poco a poco, se fue abriendo ${ }^{8}$, buscando atraer hacia sí el interés de los extranjeros; se estableció una dinámica que intentaba otorgar beneficios al comercio en ciertos rubros, como el de la librería ${ }^{9}$, concentrándose el interés foráneo en la ciudad de México, dada la importancia que poseía la capital del nuevo país en tanto espacio político y cultural. De esta manera, libreros españoles, franceses, estadounidenses compitieron en la ciudad de México buscando cada uno hacerse de clientela, estableciendo una dinámica de relación entre lectores y comerciantes de impresos de la ciudad de México e instaurando estrategias para vender la producción -publicidad, suscripciones, publicaciones atractivas, lecturas para distintos públicos ${ }^{10}$.

Debemos decir que si bien existía un interés de parte de Francia por establecer relaciones comerciales, antes de aventurar el reconocimiento envió agentes con el «objeto de obtener información sobre las posibilidades de que Francia pueda entablar relaciones comerciales» pues temía que la separación entre México y España no fuera definitiva, aunque sabía que si tardaba, otras naciones como Gran Bretaña y Estados Unidos -que habían dado el

8. En 1844 se dispuso hacer un padrón comercial de extranjeros con el fin de visualizar cuántos extranjeros había en la ciudad y qué comercios y talleres tenían. Ver Archivo Histórico del Distrito Federal, Sección Comercios e Industrias, vol. 522, Exp. 8, s/n de foja. Según la guía de forasteros, el Ministerio de Relaciones Exteriores registró, hacia mediados del siglo XIX, la llegada de 5412 extranjeros procedentes de Europa, 3047 españoles, 803 franceses, 504 ingleses, 416 alemanes, 397 estadunidenses. Ver Juan N. Almonte, Guía de forasteros y repertorio de conocimientos útiles, México, Ignacio Cumplido, 1852.

9. Es necesario señalar que en la importación de libros durante la época colonial, existía un proceso muy largo para poder obtener la liberación de los cajones de la aduana, la Inquisición vigilaba la entrada de los materiales impresos. En la etapa independiente cambió la situación, aunque continuaba vigilándose la entrada de libros que pudieran perjudicar a la Iglesia o al gobierno. Ver Gómez, op. cit.

10. Lilia Guiot, «El competido mundo de la lectura: librerías y gabinetes de lectura en la ciudad de México» en Laura Suárez de la Torre (Coord.), Constructores de un cambio cultural: impresores-editores y libreros en la ciudad de México 1830-1855. México, Instituto Mora, 2003, pp. 437-510. 
reconocimiento al nuevo país y cuyos ciudadanos entraban sin problemas a México para hacer negocios- aprovecharían las ventajas que el mercado mexicano ofrecía. Por ello, si las relaciones diplomáticas oficiales se dieron al despuntar la década de los años 30, a partir de 1826 podemos ya hablar de la existencia de relaciones comerciales entre Francia y México, aun sin que mediara un tratado diplomático, sin que hubiera representación oficial.

Poco a poco el comercio con Francia creció ${ }^{11}$. La presencia en México de distintos negociantes fue una realidad, y el de impresos comenzó a fluir, pues la libertad de imprenta era una realidad ${ }^{12}$. Los libros empezaron a llegar a México con el fin de aventurarse en un nuevo mercado sin tantas trabas, abierto a nuevas ideas, y con el objetivo de reconocer los gustos y las necesidades de los lectores mexicanos. Esta prisa por entablar relaciones implicó la puesta en marcha de estrategias diversas. En esta incursión comercial unos lo hicieron a la vieja usanza, enviando algún emisario con libros para su consignación y venta a través de algún librero asentado, y otros, se aventuraron a establecer desde el inicio la librería en la ciudad de México. Ello nos revela que unos estaban apenas examinando el terreno, como fue el caso de Frédéric Rosa, y otros, como Hector Bossange, que seguramente contó con información específica, ya que Bossange desde 1827 estableció su librería. Sea como fuere, lo que sí es una realidad es la presencia cada vez mayor en el ámbito mexicano de libros franceses y o de autores franceses traducidos, que son ingresados al país a través de los libreros galos y españoles asentados en la capital, y comerciados, a su vez, por ellos mismos o por libreros mexicanos, libreros todos que empiezan a tejer redes para los negocios y que serán los responsables de establecer un intercambio formal entre Francia y México ${ }^{13}$. En tan solo unas décadas, México logró posicionarse como un mercado importante para Francia como lo revela la siguiente tabla:

11. Ver Inés Herrera Canales, El comercio exterior de México 1821-1875, México, El Colegio de México, 1977.

12. Hay que mencionar que los escritores mexicanos comenzaron a ejercitarse y a publicar en los talleres de imprenta que surgieron a la par de la nueva nación. De ahí que el comercio de impresos se enriqueció desde dos vías la extrajera y la nacional.

13. Existía una tradición en Francia de publicaciones en español que, y a partir de 1808, se amplía. Ver Aline Vauchelle-Hocquet, Les Ouvrages en langue espagnole publiés en France entre 1814 et 1833, Aix-en-Provence, Université de Provence, 1985. 
CONSTRUIR UN MERCADO. LA LIBRERÍA DE FRÉDÉRIC ROSA (I 824-I 850 )

\section{Países con los Cuales las relaciones comerciales de Francia han SIDO LAS MÁS ACTIVAS EN I $85 \mathrm{I}^{\mathrm{I} 4}$}

En relación al comercio de libros:

\begin{tabular}{|c|c|c|}
\hline Bélgica & $252143 \mathrm{~kg} \mathrm{---}$ & 1266 539fr --- 6\% de la exportación \\
\hline Inglaterra & $133808 \mathrm{~kg}---$ & 713490 \\
\hline Estados Sardos & $124863 \mathrm{~kg}---$ & 627865 \\
\hline México & $82299 \mathrm{~kg}---$ & 487347 \\
\hline Rusia & $63330 \mathrm{~kg}---$ & 316650 \\
\hline Estados Unidos & $62325 \mathrm{~kg}---$ & 315785 \\
\hline Suiza & $57456 \mathrm{~kg}---$ & 288774 \\
\hline España & $51656 \mathrm{~kg}---$ & 277544 \\
\hline Alemania & $40100 \mathrm{~kg}---$ & 208099 \\
\hline Toscana & $33968 \mathrm{~kg}---$ & 186002 \\
\hline Argelia & $30944 \mathrm{~kg}---$ & 156790 \\
\hline
\end{tabular}

Bastaron únicamente tres décadas para que Francia lograra una posición notable en el mercado mexicano. Es interesante mirar cómo, a pesar de estar alejado de los tres primeros países, en cuanto al volumen de venta, México alcanza un cuarto lugar muy pronto - por encima de otros países del viejo continente-, manifestación clara de que verdaderamente se estaba construyendo un mercado fuera de Europa, orientado a América, más específicamente a México. El éxito emprendido se debió tanto a las necesidades de México en tanto nuevo país con aspiraciones educativas, culturales, políticas y tecnológicas, como a la crisis que caracterizó al ámbito editorial francés en las décadas de 1820-1830, así como a la presencia en Francia de españoles exiliados, capaces de traducir obras del francés al español. La conjunción de estas circunstancias llevó a los editores a buscar nuevos mercados de habla hispana, más allá de España -que por entonces tenía leyes duras para la imprenta-. La América hispana ofrecía nuevos horizontes, ofrecía potenciales clientes. Para entender esta conquista tenemos que ańadir que a pesar del crecimiento paralelo de la industria editorial mexicana, ésta no logró satisfacer las crecientes demandas editoriales -los talleres eran pequeños y las técnicas atrasadas- y, por lo mismo, se entabló una nueva dependencia hacia Europa, ya no con Espańa, sino esta vez con Francia, en tanto representante de vanguardia cultural.

14. Feuilleton du Journal de la Librairie concernant tout ce qui se rattache aux intérêts de l'imprimerie et de la librairie ancienne et moderne, fonderie, gravure, musique etc. Rapportant les textes de tous les arrêts et jugements judiciaires qui intéressent la librairie, limprimerie, la musique, etc. Samedi 22, 1853 p. 37. 
El comercio francés en este ámbito, contempló variados productos: libros, papel, grabados, litografías y mapas, productos todos que favorecieron el intercambio "comercial-cultural» con México. De esta manera, el espectro mercantil editorial se amplió y las posibilidades comerciales entre Francia y México en este ámbito crecieron, como lo muestran los siguientes cuadros:

\section{Comercio francés de PAPelería ${ }^{\text {IS }}$}

$\begin{array}{llc}\text { Inglaterra } & 480882 \mathrm{~kg} & 1108231 \mathrm{fr} \\ \text { Estados Unidos } & 405770 & 1102093 \\ \text { Brasil } & 472325 & 1060000 \\ \text { Perú } & 314319 \text { [sic] } & 785797 \\ \text { Argelia } & 464657 & 747159 \\ \text { Turquía } & 355170 & 740364 \\ \text { Chile } & 296556 & 723722 \\ \text { Estados Sardos } & 288665 & 634256 \\ \text { México } & 218919 & 530923 \\ \text { Bélgica } & 219535 & 513184 \\ \text { Espańa } & 157479 & 394660 \\ \text { Egipto } & 136526 & 282554\end{array}$

Grabados, Litografías y MAPAS ${ }^{\mathrm{I}}$

$\begin{array}{lcc}\text { Bélgica } & 30190 \mathrm{~kg} & 1042010 \mathrm{fr} \\ \text { Inglaterra } & 25083 & 872225 \\ \text { Estados Unidos } & 18841 & 648315 \\ \text { Espańa } & 17740 & 570100 \\ \text { Estados Sardos } & 10228 & 348740 \\ \text { México } & 6982 & 348740 \\ \text { Alemania } & 5138 & 229050 \\ \text { Rusia } & 4132 & 144620 \\ \text { Turquía } & 3023 & 99745\end{array}$




\section{RENOVAR LAS LECTURAS}

Para entender la importancia en el cambio de la perspectiva editorial en México, debemos señalar que en el siglo XIX el ámbito de los impresos sufrió un cambio radical, alejándose drásticamente de la historia que había tenido hasta ese momento, pues la producción mexicana creció considerablemente, incrementando la variedad de lecturas, aunque sin lograr satisfacer el mercado. Baste decir que las imprentas y librerías aumentan notablemente en la capital del país y que de contar con una decena de tiendas de libros, se multiplican hasta sumar unas sesenta al mediar el siglo, -grandes, medianas y pequeñas-, lo que nos habla de un crecimiento real que redunda en variedad y cantidad de impresos. Las necesidades propias de la población -de índole religiosa, educativa, cultural-, así como de los intereses del nuevo Estado en construcción y el impulso mismo de las imprentas y librerías de la ciudad, favorecen el desarrollo y la diversificación de presentaciones de la letra impresa. Las publicaciones periódicas crecen, día a día, en número ${ }^{17}$ de los escasos periódicos que había en el México colonial, se pasa a centenas entre 1822 y 1855 en toda la república-; los calendarios se multiplican, las revistas literarias surgen como nuevo modelo para la instrucción y el entretenimiento, en tanto que la producción de libros y de folletos aumenta notablemente. Todo ello representa una transformación desde el ámbito cultural, pero también desde el punto de vista de la producción y comercialización, así como del cambio en el concepto de lectores, ahora más incluyente y diversificado. En este último punto la consideración del público femenino, infantil y artesanal ${ }^{18}$ ofrece nuevas expectativas a los editores quienes lanzarán constantemente nuevos proyectos editoriales que estarán enfocados a estos otros lectores.

Se trata de una etapa de ensayo y error que producirá numerosas propuestas editoriales a veces exitosas y otras fallidas, la mayoría efímeras, pues hay que recordar que estamos en un tiempo de construcción de mercado, y, por lo

17. De 342 publicaciones periódicas surgidas en la república mexicana entre 1822 y 1855 , que revisó Lilia Vieyra, 87 son semanarios, 71 bisemanarios, 60 diarios, 29 trisemanarios, 9 quincenales, 6 revistas mensuales, 3 anuarios, 2 bimestrales, 1 trimestral y 15 con frecuencia irregular. Ver Lilia Vieyra, «La frecuencia de las publicaciones periódicas, 1822-1855» en Laura Suárez de la Torre (Coord.), Empresa y cultura en tinta y papel 1800-1860, México, Instituto Mora-UNAM, 2001, pp. 445-456.

18. A lo largo de la primera mitad del siglo XIX surgieron materiales de lectura para nińos, cartillas, catones, revistas literarias, calendarios, revistas y periódicos para las señoritas; y bibliotecas y periódicos para los artesanos. Ver los trabajos de Beatriz Alcubierre, Lucrecia Infante, Lilia Granillo, Gabriela Cano, Kenya Bello. 
mismo, de lectores y de lecturas; una etapa de conocer con qué se cuenta, qué se quiere leer, quiénes leen y, sobre todo, qué lecturas son redituables. Un mercado en el que se interesan tanto libreros y editores-impresores mexicanos como extranjeros por la viabilidad que se ve en el negocio. Por ello, el comercio de impresos gozó de esplendor en el periodo comprendido entre 1822 y 1855 ; algunos editores y libreros lograron mantenerse y consolidar la empresa, ofreciendo cantidad y variedad en los impresos. Tal fue el caso, por ejemplo, de los mexicanos Mariano Galván, Ignacio Cumplido y Vicente García Torres, y de extranjeros como Bossange, Rudolph Ackermann, e incluso el propio Frédéric Rosa ${ }^{19}$.

Para entender cómo se gestó esta relación comercial Francia y México me referiré al caso del librero francés Rosa quien incursionó en el mercado mexicano a partir de la década de 1820 .

\section{LA LIBRERÍA DE ROSA}

En esta perspectiva de encontrar nuevos mercados, Frédéric Rosa, librero francés, visualizó México para comercializar sus publicaciones. Comenzó, a partir de 1818, a publicar obras en español con una intención muy clara de emprender el negocio fuera de Francia y paliar así los estragos de la crisis editorial que caracteriza al mercado francés de la década de los años 1820. Ofrece en venta ediciones en español que resultaron interesantes a su intermediario inicial, el librero mexicano Mariano Galván, el más importante de la ciudad de México, en las décadas de los años 20 y 30 del siglo XIX.

$\mathrm{Su}$ producción editorial primaria denota la inquietud por conocer un nuevo mercado al poner en circulación obras de reputados autores que seguramente atraerían la atención de los lectores de habla hispana -de los mexicanos específicamente- de aquellos que tomaron las riendas de la nueva nación ${ }^{20}$. Humboldt, Las Casas, De Pradt, Llorente, Maquiavelo, o incluso textos otrora prohibidos como la obra El compadre Mateo, se encuentran

19. Durante la primera mitad del siglo XIX surgieron gabinetes de lectura que si bien no lograron tener el éxito esperado, sí representan un impulso para las empresas editoriales mexicanas y extranjeras. En estos esfuerzos por instalar los gabinetes están presentes tanto mexicanos como Lucas Alamán o José Joaquín Fernández de Lizardi, como el francés Isidoro Devaux. Ver Lilia Guiot, en Laura Suárez de la Torre (Coord.), Constructores de un cambio cultural: impresores-editores y libreros en la ciudad de México 1830-1855, México, Instituto Mora, 2003, pp. 496-504.

20. Entre 1821 y 1822 dio a conocer en español las obras nada menos que de Humboldt, De Laurens, Diderot, Montesquieu, Goldsmith, Say, Beccaria, obras de interés para un país en construcción, y la controvertida obra de Bartolomé de las Casas. 
entre los primeros autores y títulos en español. Su producción inicial no rebasa los 2000 ejemplares por obra, aunque para ser un comienzo habla de una intención de lanzar un tiraje considerable.

A primera vista la intención del librero francés es llamar la atención con obras controvertidas, prohibidas y vanguardistas. Habla de un espíritu abierto y aventurero, que va conociendo el mercado de ultramar y que paulatinamente lo lleva a construir las redes de comercio que requiere ${ }^{21}$. Su producción inicial la desarrollará claramente en función de las demandas que le va dictando el público consumidor y podemos decir que esa será su lógica. Desde 1823 ofrece obras de fácil comercialización como el Ordinario de la misa, la Imitación de Jesucristo de Kempis, el Compendio de la historia de España, el Diccionario de la lengua castellana, combinado este perfil más tradicional, con aquellas publicaciones de los autores arriba mencionados. Incluso se arriesga con la publicación de escritores mexicanos como Agustín de Iturbide y Manuel Eduardo de Gorostiza lo que revela el interés por probar con materiales nuevos. Su oferta incluye una mezcla de escritores novedosos como Chateaubriand, controvertidos como Grégoire o arraigados como Ripalda. Todo esto nos habla del interés por conocer al mercado al ofrecer una rica y variada gama de obras, pero sobre todo por lograr poner en circulación impresos diversos y atractivos, económicamente redituables. Su producción entre 1821 y 1830 se va haciendo de acuerdo a un criterio comercial y, al mismo tiempo, inscrito en las demandas que le hace el público lector mexicano. De ahí los cambios en la producción y la orientación temática de las lecturas.

En este tiempo de tanteo del mercado mexicano y de crisis editorial en Francia, Frédéric Rosa envió a su hijo, Jean, a México con la firme intención de encontrar la vía a través de la cual comerciar su producción. Su estilo responde a la vieja usanza, es decir, dejar a consignación con un librero sus ediciones. Mariano Galván se convertirá en el primer eslabón de la cadena empresarial que establecerá en México a lo largo de la primera mitad del siglo XIX. Galván, el más importante librero de la ciudad de México, entabló tempranamente una relación mercantil con Rosa. Sabemos que realizó contratos con él para editar obras en Francia, pues a Galván le resultaba más económico publicar en Francia que en México ${ }^{22}$. La mancuerna Galván-

21. Si bien no sabemos cómo entra en contacto con los libreros mexicanos, sí sabemos que tenía noticias en torno a las necesidades del mercado mexicano, pues muy pronto entabla relaciones comerciales con Mariano Galván y combina la producción en función de los intereses mexicanos.

22. Ver Laura Suárez de la Torre, «Tejer redes, hacer negocios. La librería internacional Rosa (1818-1850), su presencia comercial e injerencia cultural en México», en Lise Andries 
Rosa permitirá al francés entrar con pie firme en el mercado mexicano y Galván aprovechará enseñanzas, siguiendo las pautas editoriales consagradas de Rosa. En este sentido es muy importante señalar que el negocio de la librería en México se encontraba en una etapa de expansión y que, por lo mismo, lanzar nuevas propuestas editoriales llevó a los libreros mexicanos a buscar referentes en el ámbito foráneo. Francia se convirtió en el mejor ejemplo a seguir ${ }^{23}$.

Suponemos que de esta primera incursión de los libros de Rosa en México, las ventas produjeron ganancias pues a pesar de que Rosa declaró en París la quiebra de su librería y Galván pasó por un periodo crítico, la producción de libros en español se mantuvo bajo el sello editorial Rosa, lo que da indicios de que sus ediciones lograron aceptación en el mercado mexicano. Asimismo, la publicación del Catálogo de la librería de Rosa en 1836, revela una producción variada y, ante todo, el interés del editor por dar a conocer, de manera pormenorizada, el fondo de obras en español que buscaba vender en el mercado. El Catálogo incluye su producción, rústica y de lujo, así como las reediciones de algunas obras, y las ediciones de otros editores franceses y españoles. Este último punto nos habla de que Rosa no solo vendía su producción, sino que la enriquecía con las publicaciones de otros libreros franceses que publicaban en español. Muestra la construcción de una red de libreros en Francia, pero también de la relación cada vez más sólida entre editores europeos, interesados en el mercado de habla hispana tan importante en el siglo XIX, editores establecidos en distintos puntos de Francia -París, Bordeaux, Toulouse, Perpignan, Marseille, Montpellier- de España -Madrid, Gerona, Valencia, Coruña- y de Inglaterra -Londres-e incluso de Estados Unidos -Filadelfia, Nueva York ${ }^{24}$.

Las ediciones que comercializa revelan las necesidades de un público que fue construyendo a partir de las obras que vendió; manifiestan las relaciones culturales que se establecieron a partir del comercio de libros, entre autores y lectores y entre temáticas y gustos. No es extraño entonces que el catálogo amplíe el espectro de géneros y autores pues rebasa muy pronto aquellas

\footnotetext{
y Laura Suárez de la Torre (Dir./Coord.), Impressions de Mexique et de France. Imprimés et transferts culturels au XIX eièclel Impresiones de México y de Francia. Edición y transferencias culturales en el siglo XIX. Paris, Maison des Sciences de l'Homme/Instituto Mora, 2009.

23. El Calendario de las señoritas mexicanas de Mariano Galván es el mejor ejemplo de la mancuerna establecida entre los libreros de ambos países pues se hizo a la manera de los Almanach des dames de Rosa que habían gozado de gran aceptación en el mercado francés.

24. Es interesante mirar cómo en los distintos países de la América hispana se va incrementando la presencia de libros extranjeros a través de la acción emprendida por los libreros europeos. Ver los casos chileno y argentino.
} 
obras que comenzó a publicar, que estaban más en relación con el público que imaginó, muy politizado, muy en consonancia con el momento político que vivía México, en tanto nación recién independizada y con un Estado en construcción. De esta manera, el Catálogo revela que la mayor parte de las obras están en función de otros intereses a los que denominaré «más ligeros», el género que está de moda: la novela. Fennimore Cooper, Walter Scott, Victor Hugo, Chateaubriand son algunos de los autores que está publicando constantemente. Al mismo tiempo no deja de ofrecer las obras de demanda continua como Fleury y Ovidio. Esta diversidad me lleva a pensar en que son los lectores los que marcan la pauta.

Sin duda las novelas han logrado instalarse en el gusto del público pues resulta muy revelador que en el catálogo se dedique un espacio muy especial a las obras de Cooper (11) y de Scott (9), junto con las de la duquesa de Abrantes ( 2 en prensa). Ello nos habla de un librero interesado en ofrecer al público mexicano lo que se estaba publicando en Francia, revela la importancia del fenómeno de la traducción -del francés, inglés o incluso alemán al español-, y denota también el interés y el gusto de los lectores mexicanos por la literatura del momento. Esa oferta habla de la renovación de un mercado con la presencia de los autores de moda, de la difusión del romanticismo y de la construcción de un circuito cultural que se consolidó, día con día. No es extraño ver cómo la demanda de lecturas ya no está en función de la religión, sino en relación con la literatura y en ello la labor emprendida por los nuevos libreros fue un factor fundamental. El catálogo muestra un claro interés por la literatura pues más de 140 títulos están en relación con ella, mientras que los temas de religión suman solamente 40 y la historia y geografía alrededor de 60, mucho menos oferta se hace de otras disciplinas.

El Catálogo de la librería habla del mercado mexicano que va definiendo sus propios gustos y va dirigiendo al editor hacia dónde orientar la producción y, al mismo tiempo, buscar los libreros que le puedan proveer de los materiales en español que demanda el mercado. Es con su producción y la de otros editores, que puede hacer llegar a los escritores de moda, pero también dar a conocer la literatura, la ciencia, la tecnología, la religión que busca el mercado, estableciendo a través de la lectura puentes entre Europa y México, entre Estados Unidos y México, otorgando a los lectores mexicanos nuevos horizontes culturales al enriquecer la oferta de publicaciones.

Podemos pensar que ha ido respondiendo a los intereses de los lectores, habituales y nuevos, que éstos han ayudado a afianzar el negocio en Francia y en México, pues al despuntar la década de 1840, el nieto de Rosa, Jules, ha abierto una librería en la ciudad de México, quedando atrás las 
consignaciones. A partir de esta década la empresa logrará afianzarse en México y crecer, no sin problemas, a través de distintas alianzas en Francia, hasta llegar a ser, al finalizar el siglo XIX, la más importante comercializadora de libros, bajo el sello editorial Viuda de Bouret ${ }^{25}$.

La tímida empresa que inició con tanteos, logró consolidarse en el tiempo y se convirtió en una vía para mantener una literatura tradicional, pero también para incorporar nuevas lecturas entre los mexicanos. Ante todo debo destacar el interés que privó por entablar relaciones culturales entre Francia y México a través de las publicaciones y que, al mismo tiempo, el comercio de libros constituyó una forma más de hacer negocios en América, aunque no sin dificultades. Poco sabemos todavía de los agentes comerciales con los que contó, pero al finalizar el siglo la otrora pequeña librería de Frédéric Rosa convertida en el flamante negocio de Charles Bouret, lograba tener distribuidores en toda la República hacia los años de 1880 y se anunciaba constantemente en los periódicos. Las formas habían cambiado, pero la visión inicial de Rosa, incluso comprometido con la justicia por llevar a cabo traducciones sin permiso, traducciones que seguramente rindieron ganancias, permitió a su socio Bouret recoger los frutos y hacer del negocio de libros un buen negocio.

Conocer el modus operandi de la librería de Frédéric Rosa permite descubrir la importancia del comercio de libros en México en el siglo XIX y constatar cómo efectivamente se entablaron nuevas relaciones comerciales y culturales con Europa, específicamente con Francia, a través del comercio de impresos y cómo, según se desprende de las cifras el comercio de impresos resultó muy importante para Francia en México.

25. Ver Laura Suárez de la Torre, "Tejer redes...», op. cit. 
CONSTRUIR UN MERCADO. LA LIBRERÍA DE FRÉDÉRIC ROSA (I824-I850)

\section{BibLIOGRAFÍA CONSULTADA}

Almonte Juan N., Guía de forasteros y repertorio de conocimientos útiles, México, Ignacio Cumplido, 1852.

Andries Lise y Laura Suárez de la Torre (Dir./Coord.), Impressions de Mexique et de France. Imprimés et transferts culturels au XIX siècle/Impresiones de México y de Francia. Edición y transferencias culturales en el siglo XIX. Paris, Maison des sciences de l'homme/Instituto Mora, 2009.

Catálogo de libros que se hallan de venta en la Librería de Rosa, Paris, Impr. De Éverat, 1836.

Feuilleton du Journal de la Librairie concernant tout ce qui se rattache aux intérêts de l'imprimerie et de la librairie ancienne et moderne, fonderie, gravure, musique etc. Rapportant les textes de tous les arrêts et jugements judiciaires qui intéressent la librairie, l'imprimerie, la musique, etc. Samedi 22, 1853.

Gómez Cristina, "Comercio y comerciantes del libro en la carrera de Indias: Cádiz y Veracruz, 1750-1778» en Historia Mexicana, El Colegio de México, eneromarzo, 2008, número 227, p. 621-667.

Herrera Canales Inés, El comercio exterior de México 1821-1875, México, El Colegio de México, 1977.

Humboldt Alexander von, Essai politique sur le royaume de la Nouvelle Espagne, Paris, F. Schoell, 1811.

Pani Erika y Samerón Alicia (Coords.), Conceptualizar lo que se ve. François-Xavier Guerra, Historiador. Homenaje, México, Instituto Mora, 2004.

Penot Jacques, Primeros contactos diplomáticos entre México y Francia 1808-1838, México, Secretaría de Relaciones Exteriores, 1975, p. 42 (Colección del Archivo Histórico Mexicano. Obras Monográficas / 6).

Suárez de la Torre Laura (Coord.), Constructores de un cambio cultural: impresoreseditores y libreros en la ciudad de México 1830-1855, México, Instituto Mora, 2003.

- Empresa y cultura en tinta y papel 1800-1860, México, Instituto Mora-UNAM, 2001, pp. 445-456.

Vauchelle-Hocquet Aline, Les Ouvrages en langue espagnole publiés en France entre 1814 et 1833, Aix-en-Provence, Université de Provence, 1985.

Zahar Vergara Juana, Historia de las librerías de la ciudad de México. Evocación y presencia, México, UNAM, 2006. 
